\title{
Hypomethylation Therapy
}

National Cancer Institute

\section{Source}

National Cancer Institute. Hypomethylation Therapy. NCI Thesaurus. Code C122369.

Therapies that target the activity of DNA methyltransferases. Hypomethylating agents, including azacitidine and decitabine, have been used in the therapy of myelodysplastic syndrome and secondary acute myeloid leukemia. Although it is not curative, it can induce an improvement in hematopoiesis and lead to prolonged overall survival. Use of hypomethylating agents in the treatment of sickle cell anemia and other hemoglobin disorders can trigger the expression of fetal hemoglobin, leading to significant improvements in clinical symptoms. 